\title{
Basta a Prescriçáo da Melhor Terapia para a Esclerose Múltipla?
}

\section{Paulo Diniz da Gama}

Prof. Dr. Assistente da Disciplina de Neurologia da Faculdade de Ciências Médicas da Pontifícia Universidade Católica de São Paulo - campus Sorocaba, Sorocaba-SP, Brasil.

A esclerose múltipla (EM) é um bom exemplo de doença neurológica crônica incapacitante que necessita de muitos cuidados especializados. Nesse sentido a EM pode ser usada como um modelo de estudo dos problemas, e das possíveis soluçóes para o cuidado integrado das doenças crônicas.

A EM é a mais frequente doença neurológica progressiva e incapacitante do adulto jovem, afetando aproximadamente 30.000 indivíduos no Brasil e mais de 2 milhóes em todo o mundo ${ }^{1,2}$. A idade média de início é de 30 anos, uma idade em que muitos estão começando suas carreiras profissionais e constituindo suas famílias. Após 15 anos do início dos primeiros sintomas, $21 \%$ necessitarão de uma bengala para caminhar, podendo aumentar para 69\% após 40 anos do início dos sintomas ${ }^{2}$. Vários medicamentos têm sido desenvolvidos para reduzir a morbidade da doença e proporcionar alívio dos sintomas.

Devido a EM ser uma doença dinâmica produzindo déficits neurológicos multifocais e incapacitantes, uma vasta gama de especialistas da saúde são necessários para ajudar na assistência ao longo da vida do paciente ${ }^{3}$. O neurologista é geralmente o cuidador principal, porém não menos importantes são os especialistas em reabilitação, psicólogos, fonoaudiólogos, assistentes sociais, oftalmologistas e urologistas. Em particular a atuação da enfermeira é marcante, não só porque é a profissional do grupo multidisciplinar que o paciente primeiro entrará em contato, como será aquela que irá garantir a melhor forma do paciente receber o seu tratamento, gerenciando a programação terapêutica. A enfermeira também irá acompanhar as reações adversas dos pacientes, orientando medidas básicas para o controle ou encaminhando ao médico cuidador quando os sintomas assumirem maior gravidade ${ }^{4}$.

No entanto, tem havido algumas tentativas de definir modelos de atenção multidisciplinar para a EM ou testar a sua eficácia, com muito ainda por ser aprimorado ${ }^{3,4}$. Assim como outras doenças crônicas, a coordenaçáo e a continuidade dos cuidados para pacientes com EM são muitas vezes de qualidade baixa.

Nesta edição da Revista Neurociências, uma importante contribuiçẫo foi dada por Ivone R Fernandes et al. ${ }^{5}$, do Centro de Atendimento e Tratamento da Esclerose Múltipla da Faculdade de Ciências Médicas da Santa Casa de São Paulo, tese de doutorado defendida com propriedade em 2008. Náo apenas na proposta de diretrizes para a orientação do uso da terapia imunomoduladora, como também da validação das diretrizes por juizes experientes, em 66 itens das diversas etapas do preparo e administração da medicação. Utilizandose da técnica Delphi, o estudo alcançou um índice maior que $80 \%$ de consenso, em $90 \%$ dos itens.

Este estudo servirá não só para orientar os centros de referência que já realizam as condutas de enfermagem na orientação do uso das drogas imunomoduladoras, como também na capacitação de profissionais que pretendem iniciar nessa área de atuaçáo. A continuidade dos estudos de cuidados multidisciplinares, com o devido rigor metodológico, deve ser incentivada para confirmar e aprimorar as diretrizes atualmente propostas.

É oportuno se destacar que esta mesma linha de cuidados, atitudes voltadas ao bem estar do pa- 
ciente, envoltas no rigor da pesquisa clínica, já vem sendo desenvolvido pelo professor Charles Peter Tilbery, coordenador desse mesmo grupo multidisciplinar ${ }^{6}$. A monitorização dos efeitos adversos da terapia imunomoduladora e as condutas para minimizar essas reaçóes, são medidas de grande importância para melhorar a adesão e consequente eficácia do tratamento, além de assegurar uma adequada qualidade de vida dos portadores de EM que fazem uso dos imunomoduladores. $\mathrm{O}$ estudo vem alertar para a necessidade dos colegas que se empenham em corretamente diagnosticar e iniciar o tratamento, e se esquecem de melhor acompanhar o bem estar de seus pacientes, condição primordial e mais nobre do ato médico. Os artigos endereçados por esse grupo de profissionais mostram o cuidado que vêm tomando com o acompanhamento de seus pacientes, exemplo a ser seguido por muitos outros centros de todo o país.

\section{REFERÊNCIAS}

1.Gama PD, Trigo LX, Andrade CRR, Sala CR. Epidemiological study of multiple sclerosis in the city of Sorocaba, Brazil. Arq Neuropsiquiatr 2004;62:13.

2.Compston A, Confravreux C, Lassmann H, Mc Donald I, Miller D, Noseworthy J, et al. McAlpine's Multiples Sclerosis. Londres : Elsevier Inc, 2006, p.1-981.

3.Jansen DE, Krol B, Groothoff JW, Post D. Integrated care for MS patients. Disabil Rehabil 2007;29:597-603.

4.Bodenheimer $\mathrm{T}$. The future of primary care: Transforming practice. $\mathrm{N}$ Engl J Med 2008;359:2086-9.

5.Fernandes IR, Tilbery CP, Avelar MCQ. Validação das Condutas de Enfermagem na orientação de clientes com Esclerose Múltipla em uso de imunomoduladores. Rev Neurocienc 2011;19:68-76.

6.Tilbery CP, Fazzito MM, Jordy SS, Thomaz RB, Fernandes IR. Efeitos adversos no tratamento da Esclerose Múltipla com drogas imunomoduladoras - experiência em 118 casos. Rev Neurocienc 2009;17:220-5. 